\title{
Are current design processes and policies delivering comfortable, low carbon buildings?
}

Paul G Tuohy*, Gavin B Murphy.

Energy Systems Research Unit (ESRU), Mechanical and Aerospace Engineering, University of Strathclyde, Glasgow, G1 1XJ, UK.

* Corresponding author: paul.tuohy@strath.ac.uk 


\begin{abstract}
Gaps between intended and actual performance which impact on indoor environment, energy use and carbon emissions have been well documented and are nowhere more important than when they present in performance problems such as building overheating and consequent occupant discomfort and high energy running costs. Here such gaps are explored through a review of relevant literature and related illustrative investigations. Key drivers of those performance gaps are identified and located in the stages of the building industry process. Three case studies, of one office and two houses, are provided highlighting where faults arise and may or may not be effectively dealt with and the reasons why. These include faults at the Implementation, Validation and Operation stages and the paper concludes by summing up generic failings in the industry that lead into the following paper by the same authors that offers an approach and potentially effective solutions to reducing such performance gaps by correctly using a BIM approach to quality control in the construction industry.
\end{abstract}

Key words: Overheating, BIM, LEED, BREEAM, Soft Landings, Green Star, Building Simulation, Low Carbon Buildings, NABERS, Energy ratings, Quality System, Six Sigma. 


\section{Introduction, aims and approach}

Many policy and industry driven initiatives worldwide aim at improving the performance in use of new and retrofitted buildings by altering building industry processes, products and services in order to reduce energy use and carbon emissions and improve sustainability, occupant comfort, health and productivity in buildings. Numerous studies have demonstrated that the intended performance improvements are often not achieved (Bannister 2003) (UBT 2012) (Booth 2008) (EST 2012) (Turner and Frankel 2008). Such authors posit that the observed disconnects have their root causes within the policy drivers of the related industry processes. The current situation will be described and analysed here, and then improvements proposed by the authors, informed by their backgrounds in the software, electronics and automotive industries are put forward in a second paper in this journal (Tuohy and Murphy 2015).

This paper:

a) Describes the performance gaps within the building industry based on a literature review;

b) Uses three case study low energy buildings to explore those performance disconnects;

c) Relates the findings of a) and b) to the stages in the building industry process;

d) Concludes that these issues unless addressed will result in overheating discomfort and high energy use.

Within the field there are numerous definitions of the buildings industry design flow process e.g. in the UK, the RIBA Plan of Work (RIBA, 2011), Construction Industry Council work stages (CIC, 2012) and the 'Prepare-Design-Implement-Check-Operate' flow of Bordass et al. (2011), other similar definitions exist outside the UK.

As a consistent framework for this paper the model shown in Figure 1 is adopted. This has similarities to the building industry flows but has more explicit representation of the validation, feedback and feed-forward processes as found in design flows such as the NASA Design Process for Complex Electronics (NASA, 2012).

These feed-forwards (e.g. installation instructions, commissioning tests, controls software and hardware specifications, user manuals etc. from the detailed design stage) and feedbacks (e.g. knowledge of systems application ranges and limitations, performance variations with patterns of use, fail modes and risk analysis etc. fed back to concept, detailed design or implementation stages from previous projects or characterisations) form part of the quality systems approach used in BIM benchmark industries (Pyzdek 2003, El-Haik et al. 2010). 
Figure 1. Model of design flow adopted in this work

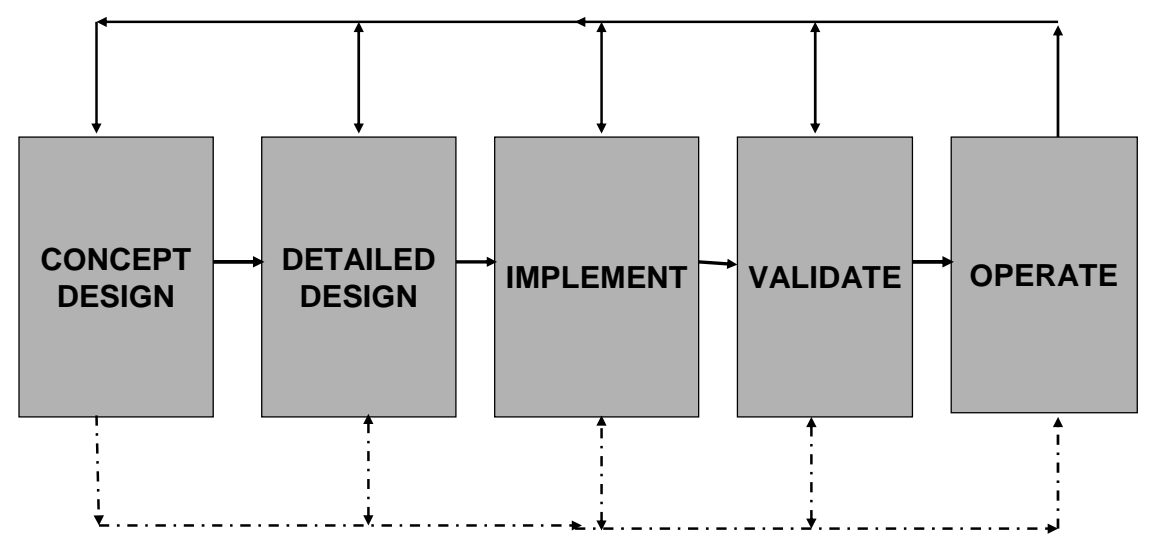

\section{Gaps between intended and actual building performance - a review.}

Researchers globally are finding that buildings which achieve a high standard or rating based on the predictive calculation methods frequently do not demonstrate the intended performance in operation. Several of their studies are reviewed here to identify the common gaps found, and their proposed causes.

UK Government funded studies that aimed to understand non-domestic building performance, particularly energy and indoor environmental performance included the Probe series of post-occupancy surveys, which exposed many strategic and tactical issues that made it difficult for even the best buildings to achieve their intended performance (BRI 2001, Bordass 2001). In the 2000s UK Government focussed on 'Rethinking Construction' (Construction Task Force 1998), seeking improved efficiency and costs, but failing to address the performance gap. One reaction to this perceived miss-step was the establishment of the Usable Buildings Trust to provide guidance on building performance (UBT 2012). The UBT influenced the adoption of the Display Energy Certificate (DEC) operational energy performance ratings process for non-domestic public buildings over $1000 \mathrm{~m} 2$ in the UK (Bordass, 2005, Bordass et. al., 2004). The DEC data has provided valuable insights into actual building performance with most being found to be consuming very much more energy than expected leading to "Halls of Shame" headlines (Booth 2008).

UK office buildings investigated included the multiple award winning Elizabeth Fry "Best Building Ever?" and ZICER buildings at the University of East Anglia (Probe14, 1998) (Tovey and Turner, 2006) (Ingham, 2010). Elizabeth Fry in its first year consumed $60 \mathrm{kWh} / \mathrm{m}^{2}$ electricity, plus $70 \mathrm{kWh} / \mathrm{m}^{2}$ heating - more than $50 \%$ higher than predicted. Subsequent performance monitoring and investigation revealed considerable scope for savings, the University commissioned remediation works substantially upgrading the heating and ventilation controls, reducing heating to $37 \mathrm{kWh} / \mathrm{m}^{2}$. 
The ZICER building at UEA built 5 years later used the similar construction but with improved insulation and glazing. Predicted heating was $30 \mathrm{kWh} / \mathrm{m}^{2}$ per year however, in the first two years of operation it used over twice as much. Another investigation was carried out and revised control algorithms were put in place, resulting in a similar energy performance to Elizabeth Fry, though with a lower level of occupant satisfaction. Both buildings are recognised as examples of good performance but this has only been achieved through the motivation and efforts of the facility management team, support from independent monitoring, and investments in remediation - attention that new buildings seldom receive.

Reviews of UK POE studies (Bordass et al. 2001, Bordass 2012), identified inherent problems in the way buildings were procured and concluded that "Controls, manageability and usability need much more attention at all stages". Recurring problems with new buildings were summarised as: problems with interfaces between work packages; problems with control systems, management and user interfaces; handover processes too abrupt; user dissatisfaction; unmanageable complexity; and not surprisingly energy use higher than anticipated. One recommendation was a 3 year 'sea trial' commissioning and review process to achieve optimal performance. This is now incorporated within a Soft Landings whole life performance appraisal process being developed and applied in the UK (BSRIA 2012).

The Energy Consumption Guide 19 for offices (Carbon Trust 2003) provided key reference performance benchmarks for current regulations, dividing office buildings into four categories: naturally ventilated cellular; naturally ventilated open plan; air conditioned standard; air conditioned prestige. The measured energy benchmarks for naturally-ventilated buildings are significantly lower than for air conditioned types, so one might have expected regulations to favour naturally ventilated buildings. Instead, the regulations take account of predicted performance relative to a reference building of the same type, with higher energy use allowed for mechanically cooled buildings. The current UK regulatory approach thus appears to encourage buildings with mechanical cooling at the design stage while existing evidence largely suggests that they will have higher energy use. On the other hand, weaknesses in the UK regulatory methods for assessing risks of overheating means that where naturally ventilated designs are selected there is a high risk that they will overheat and require cooling to be retrofitted, again resulting in more energy use than intended and predicted (Tuohy 2009, 2008).

CarbonBuzz, a recent initiative in the UK which includes a voluntary repository for predicted and actual energy use data, demonstrates that actual energy use is typically more than $50 \%$ higher than that predicted (CarbonBuzz, 2012).

Such discrepancies are not unique to the UK. The German Federal Ministry for Economy demonstration program covered 22 buildings with passive cooling technologies designed to be low energy, monitoring energy use, environmental conditions, occupant behaviour and comfort. It was observed that the high focus on these buildings highlighted many errors in system and controls operation. "In many cases, detailed analysis of the electricity consumption helped to identify weaknesses in the system operation: operation of the heating system pumps outside the heating season, heating of pre-cooled air by an earth-to-air heat exchanger during summer, etc. In large buildings operational faults cause energy consumption and energy costs of an order of magnitude which is not negligible. From the experiences it can be assumed that these kinds of faults are common practice in the 
operation of the building stock as a whole." (Voss et al, 2007). It is clear the passive cooling system operation could be compromised by poor implementation and operation. Their conclusions infer that these faults are common across all buildings, remaining invisible and persisting in the majority of buildings that are not subject to this level of scrutiny.

In the USA, a review of the performance of LEED (USGBC, 2012) accredited buildings found those predicted to be most energy efficient had the greatest discrepancies between predicted and actual performance, with actual energy use twice the prediction in some cases (Turner and Frankel, 2008).

In Australia, Bannister (2003), found generally poor or no correlation between the design score and the operational performance benchmarked by Australian Buildings Greenhouse Rating (ABGR) (now incorporated in the National Australian Building Environmental Rating Standards NABERS (NABERS 2012)). In a later paper Bannister (Bannister 2009) identified some reasons why, including poor controls design, implementation and commissioning; poor build quality; complexity; poor maintenance and operations; invisible problems; inoperable or un-maintainable plant and systems; bad design; and over specification. Again these echo the findings of Probe in the UK. To remedy the causes of these disconnects NABERS has developed a "Commitment Agreement" protocol (Bannister 2005) which requires expert reviews in the design stages and prescribes the scope and reporting of predictive analysis. The NABERS rating is awarded on actual performance once the building is occupied.

For domestic buildings there are similar problems and disconnects that may be getting worse as legislation makes the buildings more complicated and technologies traditionally deployed in the non-domestic sector are applied. Of UK government agencies, the Energy Savings Trust (EST) and the Technology Strategy Board (TSB) are monitoring performance of systems in operation and reporting on results (EST 2012). These include studies on micro-CHP systems, gas boilers, micro wind turbines, heat pumps, solar PV and thermal systems, and mechanical ventilation systems. In general they have revealed much poorer performance than expected, for example with COPs in practice typically $33 \%$ less than predicted in the heat pump trials, the mechanical ventilation evaluation reported that in many of the installations inspected there were serious flaws found (Zero Carbon Hub 2013).

As insulation standards improve domestic buildings become more sensitive to overheating even in cooler climates. In Denmark a recent survey of the performance of 8 dwellings built to Passiv-Haus $(\mathrm{PH})$ standard found significant overheating problems despite these buildings complying with the PH design criteria (Larsen 2012). Maivel (2015) reported overheating in Estonian apartments etc.even in this high latitude Nordic country.

In conclusion, studies show that performance disconnects are a common experience in the current buildings industry, that significant problems exists in the implementation of comfortable low carbon buildings and their systems and controls unless significant effort and finances are put into non-standard investigation and remediation of them. 


\section{Gaps between intended and actual building performance - an investigation.}

Three case studies investigated by the authors, promoted as exemplars of domestic and non-domestic buildings, are now presented: i) the Environmental Office, ii) the 1st Certified $\mathrm{PH}$ in Scotland and iii) the Glasgow House, used for training of construction workers.

Risk analysis was used to explore the performance gaps, assess potential failure modes and establish how these failure modes would be detected. Controls were viewed as a high risk area and special attention given to mapping them and checking for their correct implementation and operation. The controls mapping method was used to chart on a zone by zone and mode by mode basis the intended environmental conditions and the intended responses of the controls and systems to deviations from the specified intended environmental conditions. The controls map could then be used to comprehend intended operations and to provide a performance baseline for the observed operation. The approach taken was based in part on the quality systems approach utilised in other industries where failure mode effect analysis (FMEA) is used to scope and manage risks and fault testing are required elements within their quality systems (Pyzdek 2003, El-Haik 2010). These industries include aerospace, automotive and electronics which are among those identified as BIM benchmarks (BSI 2012). The FMEA and Control Mapping approach applied here is described in more detail in Tuohy (2013), gross problems are highlighted.

\subsection{The Environmental Office Building, Garston, England}

The BRE Environmental Office, using assisted naturally ventilation (ANV), was intended as an exemplar for future buildings and is still identified by some as such (RAE 2010). Monitoring after completion showed it performed reasonably well for occupant satisfaction and energy use compared to other office buildings at the time, but operational energy use was $90 \%$ above the design target (Ní Riain et al. 2000). The authors revisited the building to investigate performance identify opportunities for improvements, and process improvements for future building projects. A feature of the building is high thermal mass exposed concrete ceilings and multiple BEMs controlled ventilation modes including cross flow, ceiling duct and fan assisted solar stack.

Intended control implementation was reviewed using the architects 'concept' document and the controls manual provided by the controls contractors, to create a controls map for use in the investigation. This required significant effort because while the 84 page manual had sections on individual control elements there was no overall description of integrated operation. The control map was constructed by synthesising the architect's document and the controls manual. Figure 2 illustrates some of the observations annotated above a section of the control map for an office zone in normal daytime operation and night cooling modes.

The authors went on to interview building occupants, building managers and controls contractors and observe the building during operation, which confirmed these issues were real, and highlighted further issues some of which are outlined here:

The controls documentation was not well understood by occupants, building managers or controls sub-contractors resulting in tactical changes made with no strategic understanding of overall system behaviour causing problems once the prevailing conditions changed. 
The control implementation was based on a concept design document implemented by controls engineers on a best-guess basis and commissioning used only to confirm that each control sub-component was operating, not the systems as a whole.

The hierarchy of the energy control strategy was not optimum with, for example, mechanical borehole cooling being applied before free cooling.

The control system was overly simplistic and coarse. For example, the night cooling mode was triggered by external conditions at $4 \mathrm{pm}$ only, so if raining then, night cooling was not triggered however high the indoor temperatures. Control of the windows was coarse, with multiple windows opening simultaneously once a threshold temperature was reached, leading to sudden draughts. Incorrectly implemented control of bore-hole cooling was observed which led to unintended operation, with boilers triggered when cooling water flowed, heating the cooling water and resulting in both systems operating to no benefit. The poor implementation of the passive and active cooling compromised thermal conditions and increased energy use.

Pumps were found running, using and gas being used when there was no heating demand due to a spurious fault condition that caused the non-condensing backup boiler and the hot water feeder circuit to remain on continuously.

Building performance and energy use was only visible through fuel bill data. The submetering was not implemented, and there was no public display other than on the BEMS PC, hidden in a locked room that was rarely visited.

Controls and metering improvements to address these issues required hardware and software changes but work was stalled due to financial and logistical constraints. Resolving strategic design or implementation issues after building handover is difficult when operation and maintenance regimes and budgets do not cover business disruption to allow the work to happen.

Figure 2. Controls map summary annotated with observations.

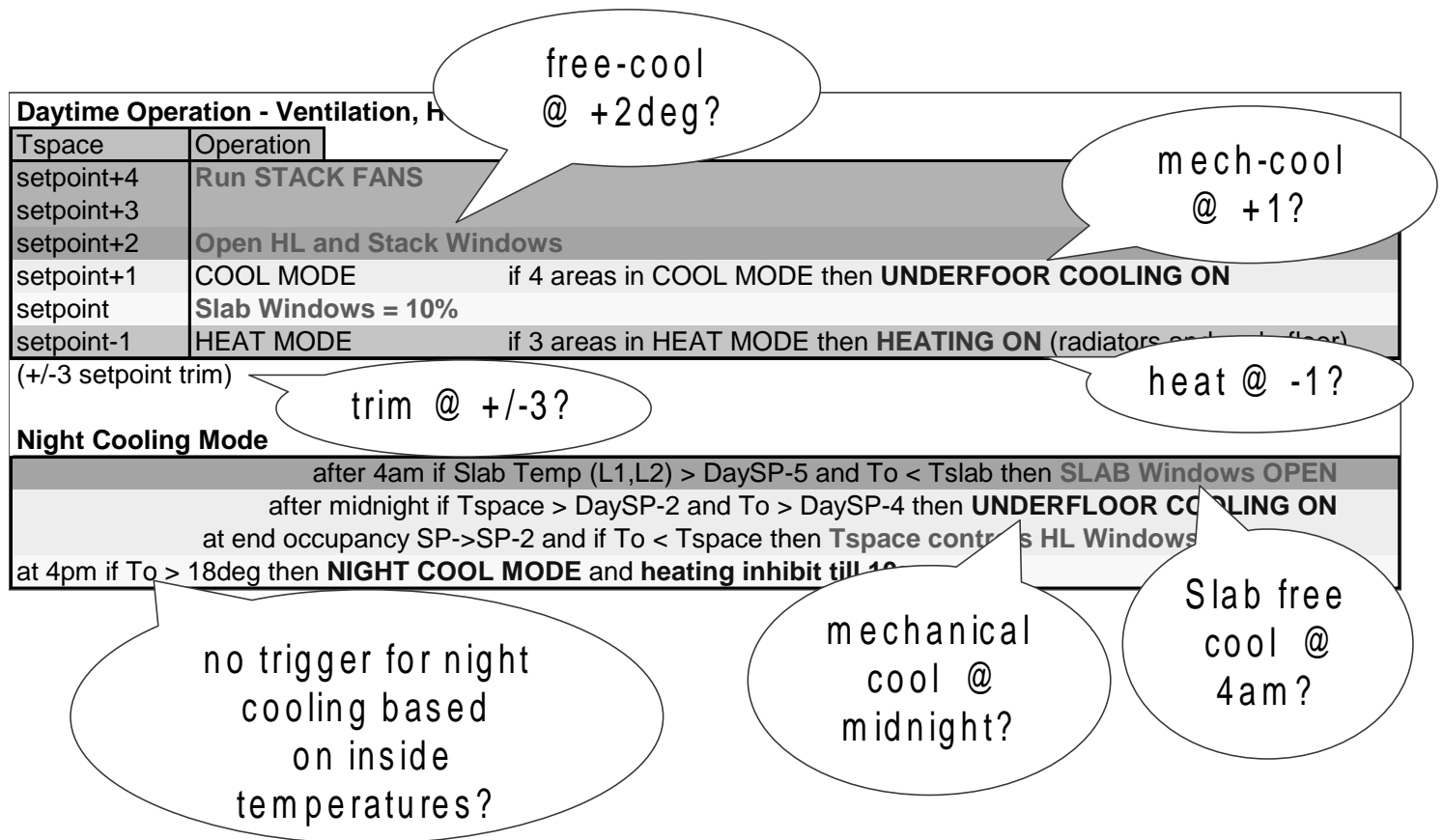




\subsection{The first Scottish Passive House (PH), Dunoon, Scotland.}

The Dunoon $\mathrm{PH}$ was the $1^{\text {st }}$ to be certified in Scotland, and received a number of awards. The $\mathrm{PH}$ uses a whole house mechanical ventilation heat recovery unit with supplementary heat from an air to air heat pump. Hot water is from a solar thermal tank and an electric immersion heater. The study aimed at evaluating these increasingly popular systems in use.

Again the approach taken was to construct a risk based potential fail mode effect analysis (FMEA) and a control map. The failure modes were identified from system knowledge and experience, and also from the critical points of $\mathrm{PH}$ specification and design which have been extensively document

ed in the PH Institute guidance and training documentation (PHI, 2012). A monitoring scheme was established to gather data on temperatures, air quality, system performance and energy use. Many fundamental problems were identified by the inspection and monitoring. Some key findings were:

The occupant was unaware of how to use the mechanical ventilation system in the summer resulting in overheating. The 200 page ventilation system manual was not helpful.

Long aluminium ducts brought cold outside air into the building, $140 \mathrm{~mm}$ insulation was specified but inspection revealed that it was only $19 \mathrm{~mm}$, and in places it was missing entirely, leading to significant heat losses, condensation on the ducts, and potential moisture damage requiring ceilings to be opened for remediation (Figure 3).

The heat pump was without a remote thermostat control, so there was insufficient feedback of space temperature to achieve desired temperatures. The system also proved unable to deliver sufficient heat in cold conditions. and the supplier could not provide performance data at $2^{\circ} \mathrm{C}, 0^{\circ} \mathrm{C}-2^{\circ} \mathrm{C}$ and $-7^{\circ} \mathrm{C}$ - only a year round average.

The solar hot water system and the immersion heater controls were independently set and not optimised limiting the solar contribution to the theoretical $40 \%$ solar fraction even with optimized control (Ayompe et al, 2011), much less than the design calculations.

This study again highlighted issues including overly coarse controls, incorrect implementation of systems and controls, lack of visibility to occupants and owners, disconnects between vendors, specifiers and installers, overly optimistic specifications, and intended performance not being met. It also confirmed the difficulty of fixing problems after a building was handed over and the need for expert intervention to put them right. It took 16 months to put things right, including replacing the heat pump and ventilation unit and reconfiguring the ventilation ducting. 
Figure 3. Issue with the ventilation system: missing transfer openings under doors, missing and inadequate cold duct insulation, moisture problems due to inadequate insulation and sealing of cold ducts required ceilings to be opened.

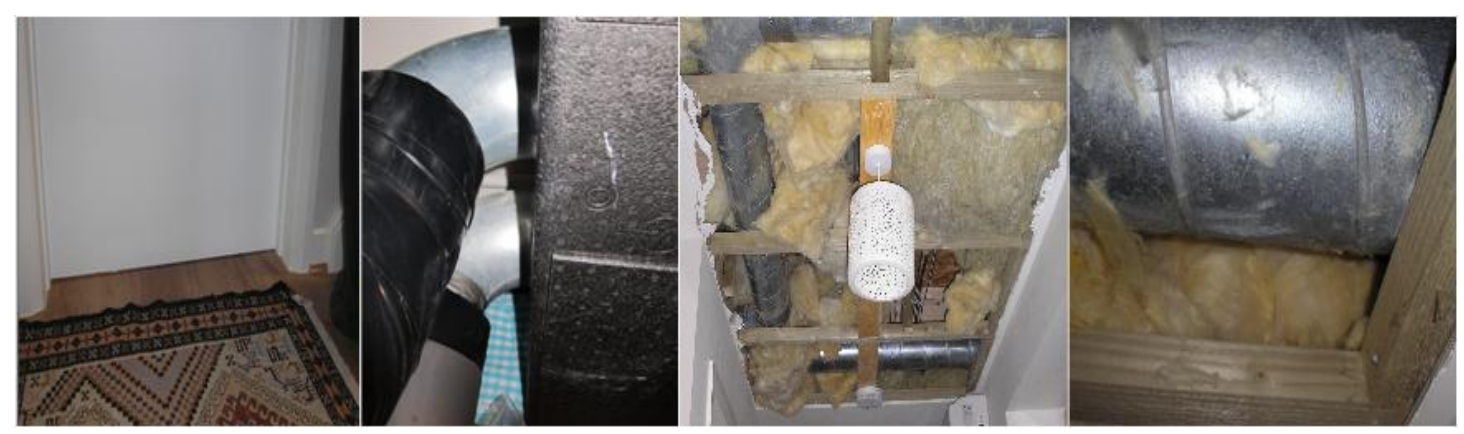




\subsection{The Glasgow House Solar Thermal and MVHR Systems, Glasgow, Scotland}

The FMEA and control mapping, inspection and monitoring method constructed for the $\mathrm{PH}$ was applied to evaluate the implementation of the mechanical ventilation and solar systems in the Glasgow House, which was designed and built as an example low energy building and as a training centre (Carr 2012). For example this house used gas backup heating instead of electricity as used in the $\mathrm{PH}$.

Very obvious faults were identified including: missing or melted insulation on both the primary heating circuit and the solar pipework (Figure 4) causing energy losses, heat gains and potential for severe overheating discomfort in warm periods; gas boiler controls not optimum for solar heat gains and user hot water demands; mechanical ventilation system positioned in an attic space without easy access to observe warnings, change filters or carry out maintenance and no door undercuts installed to provide airflow required for the mechanical ventilation system.

The re-use here of the PH FMEA and control maps method enabled lessons to be learnt from other projects by use of the clear and easy capture and transfer of information in a modular fashion. How that learning could be formalised and made effective within the industry needs further work.

Figure 4. Solar system pipework in the attic of the Glasgow house showing poor specification and poorly applied thermal insulation. Much of the insulation was found to have melted and fallen away from the pipes. Hot pipework routed around bedrooms greatly enhanced potential for overheating in summer.

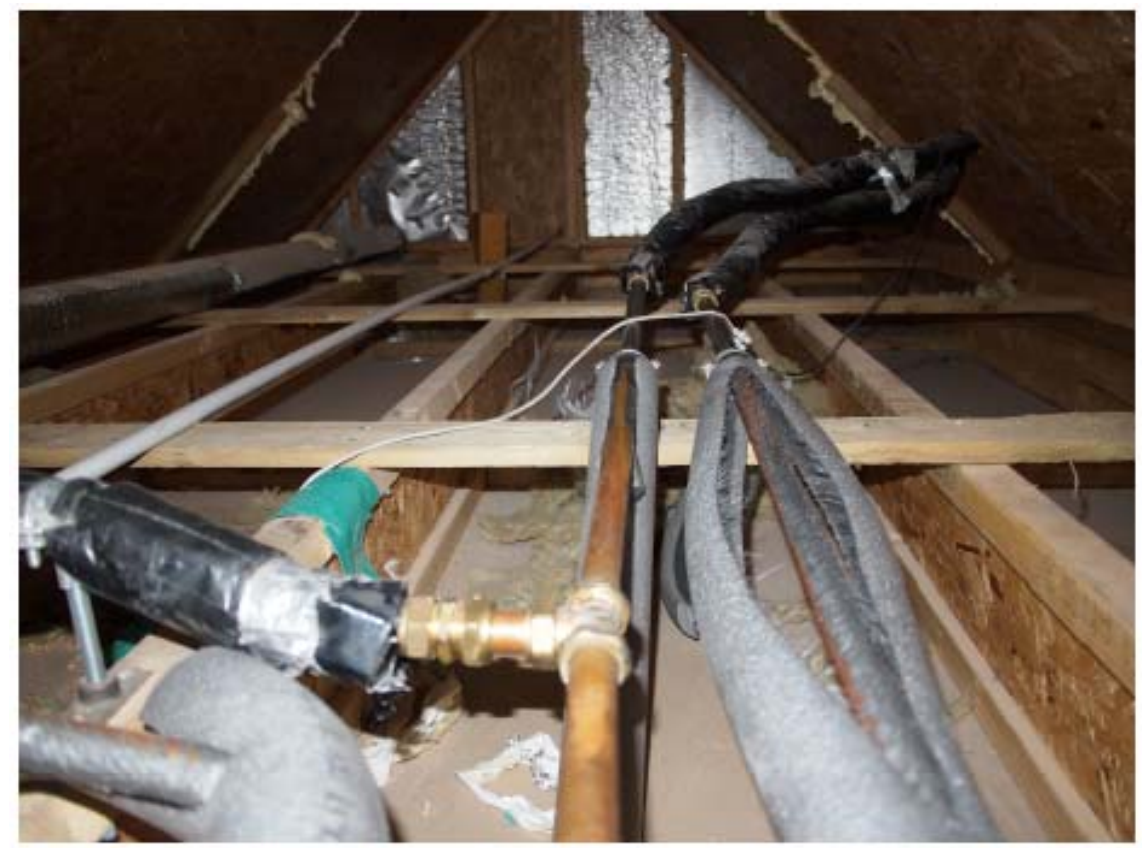




\section{Relating gaps between intended and actual performance to industry process.}

Internationally there are many common findings between the results of the reviewed studies and the buildings investigated above, some of which are summarised in relation to the stages of the simple model of the industry process proposed in Figure 1:

Concept and early design: Decisions are influenced by learning garnered from previous buildings, chosen often because of their high predictive ratings, industry awards or effective marketing, rather than their verified performance in practice. Thus non-optimal performance decisions can be replicated rather than addressed. This is complicated by the reality that predictive methods (models) and construction processes do not deliver intended performance and also that the actual comfort and energy performance information from related research is ignored and not used either to inform policy or design decisions, being often dismissed as anecdotal or irrelevant to the current project. This systematic dismissal of research intelligence is driven not least, by the litigious building markets where design faults can incur punitive reparation costs.

Detailed design: Obvious high impact gaps the knowledge of designers exist from the early design stages. Controls are often poorly understood and designed, coarse, not optimum, conflicting, not fault tolerant, overly complex, and unexplained. New technology systems are often poorly represented and controls not considered in the required detail. Overly optimistic performance assumptions are made and opportunities for underperformance, faults, and unintended consequences largely ignored. Design assumptions are often too narrow and not representative of actual variations in building use patterns. Where there are building performance limitations on how a building can be used and still perform well are often not identified and rarely communicated to the building owners and users. The use of simulation in design is often limited in scope (e.g. idealised representation of controls, plant and occupants), but these simplifications are not comprehended or compensated for in the design process. Each new project appears to start from scratch rather than re-use proven designs with understood performance, risks, issues and limitations. The detailed design stage does not appear to provide sufficient feed-forward of information to implementation, validation and operation stages.

Implementation: There appears often to be insufficient information from the detailed design stage particularly with respect to controls and new technologies. In some cases only concept design information is available. Control implementation appears to be in multiple subsections without comprehension of overall operation. There appears to be a lack of a quality culture - so faults in implementation often occur and are often undetected. There often appears to be no mechanism for learning from results from previous similar projects.

Validation (Commissioning): Problems often go undetected and unresolved. The coverage of the commissioning process does not ensure correct operation in practice including fault conditions. Feed-forward of designed commissioning specifications that capture overall control strategies and proper understanding of how different systems will operate together appears to be missing.

Operation: Faults often occur and remain invisible. Building managers and occupants don't understand: the building; the building controls; limitations in its use; intended modes of operation; and actual energy use. Where there is a control manual it is often overly complex 
and difficult to understand. This lack of understanding leads to controls being randomly tweaked without comprehension of the overall picture. This can lead to controls which are assumed to be working in harmony actually working in conflict with one another. In some cases it may not be possible to control the building optimally. Visibility of actual performance against design targets is often poor or unknown. New technology systems do not work as well as predicted and their performance is seldom monitored or reviewed. Optimum performance may only be achieved after re-engineering which can be difficult, costly, disruptive, sometimes impossible to achieve. There is often limited visibility and accountability within the design and implementation team for poor performance or poor quality.

\section{Conclusions}

The review and case studies highlight that new or retrofit buildings delivered using current industry process tend to have faults leading to compromised comfort and increased energy use. Unless exceptional scrutiny and funded remediation is carried out these faults will be persistent. These problems are associated with the design process.

One of the most obvious symptoms of the failure of buildings and their systems to meet design ambitions is in the experience of discomfort by occupants, being from heat, cold or draught. Passive cooling systems were highlighted as being commonly compromised and potential for overheating discomfort increased. Consequences of this may be the retrofit of mechanical cooling, or reduced confidence in passive approaches leading to the selection of mechanical cooling in design, either of these would lead to further increased energy use in practice.

In principle, it would be much more productive to get buildings right the first time than to have to address them post completion. However, even to begin to do this routinely will require the industry to have much better understanding of how buildings and systems actually perform in use and then to use this understanding to improve industry process.

Where innovations are concerned, there will always be risks including unexpected behaviour and unintended consequences, making risk analysis, follow-through, fine-tuning and feedback absolutely essential for these new features or combinations of features to become fully comprehended in robust processes in the buildings industry.

A method for quickly assessing and learning the risks associated with new technologies and factoring these throughout the design process would help to minimise the impact.

The overall conclusion is that current processes and policy are not routinely delivering comfortable low carbon buildings and that challenges remain to be addressed. 


\section{Acknowledgement}

The investigations carried out on the case study buildings were possible due to support from the Buildings Research Establishment, Fyne Homes, Gokay Deveci Architect, Renewable Heat Strategies and MEARU.

\section{References}

Ayompe L.M, Duffy A, Mc Keever M, Conlon M, McCormack S.J (2011), Comparative field performance study of flat plate and heat pipe evacuated tube collectors (ETCs) for domestic water heating systems in a temperate climate. Energy 36 (2011) 3370-3378

Bannister P, (2003) Lies, damned lies and simulations: Use and abuse of simulation in the marketplace. The 2003 IBPSA Australasia Seminar, University of Sydney, October 31, 2003,

Bannister P (2005) 'THE ABGR VALIDATION PROTOCOL FOR COMPUTER

SIMULATIONS' 9th International Building Performance Simulation Association Conference, 2005, Montreal.

Bannister P, (2009) Why good buildings go bad while some are just born that way.

Ecolibrium Feb 2009.

http://www.airah.org.au/imis15_prod/Content_Files/EcoLibrium/2009/February09/2009-0201.pdf

Booth R (2008) Halls of Shame: biggest CO2 offenders. The Guardian. http://www.theguardian.com/environment/2008/oct/02/carbonemissions.greenbuilding

Bordass B (2011) Design Intent to reality: Linking modelling to performance in use. CIBSE POE and dynamic simulation seminar, London South Bank University, 13 December 2011. http://www.cibse.org/content/Groups/Building Simulation Group/120305 POE and Dynami c Sim/WBordass\%20Simulation\%20and\%20POE\%20Slides\%20Shortlist\%2013Dec11.pdf

Bordass, B and Leaman, A (2012), Test of Time, CIBSE Journal 30-36, March.

Bordass B, Cohen R, Field J, (2004) Energy Performance of Nondomestic Buildings Closing the Credibility Gap, Building Performance Congress, Frankfurt, April 2004. http://europrosper.energyprojects.net/links/IEECB04BordassCredGap2.pdf

Bordass B, Leaman A and P Ruyssevelt (2001), Assessing building performance in use 5: Conclusions and implications. Building Research and Information $\underline{29}$ (2), 144-157.

Bordass W (2001), Flying Blind: everything you wanted to know about energy in commercial buildings but were afraid to ask, Association for the Conservation of Energy, London.

Bordass, W (2005) "Onto the radar: How energy performance certification and benchmarking might work for buildings in operation, using actual energy consumption", a discussion paper,Usable Buildings Trust. Downloadable from www.eplabel.org 
BSI (2012), 'Investors Report: Building Information Modelling (BIM)' http://www.bsigroup.com/upload/Standards\%20\&\%20Publications/Building/InvestorsReportBIM.pdf

BSRIA (2012) Soft Landings. http://www.bsria.co.uk/services/design/soft-landings/

Building Research \& Information (2001), Special Issue: Post-occupancy Evaluation, Volume 29, Number 2.

CarbonBuzz (2012) CarbonBuzz a RIBA, CIBSE platform. http://www.carbonbuzz.org/

Carbon Trust (2003) Energy Consumption Guide 19 (ECON19).

Carr S (2012) The Glasgow House. http://www.cicstart.org/userfiles/file/IR3_24-30.pdf

Construction Industry Council (CIC) (2012) http://www.cic.org.uk/home/index.shtml

Construction Task Force (1998) Rethinking Construction. Department of Trade and Industry. Crown Copyright 1998 URN 03/951

El-Haik B, Shaout A (2010) Software Design for Six Sigma: A Roadmap for Excellence. Wiley-Blackwell; ISBN-10: 0470405465, ISBN-13: 978-0470405468.

EST (2012) 'Field Trials'

http://www.energysavingtrust.org.uk/est/search?SearchText=field+trials

Ingham M (2010) Low Energy Buildings

http://www.buildwithcare.eu/images/article_downloads/uealowenergybuildings.pdf

Larsen T et al. (2012) Evaluation of the indoor environment in 8 Danish Passive Houses.

Passivhus Norden 2012. Trondheim Oct 21-23 2012. http://tapironline.no/fil/vis/1001

Maivel, M., J. Kurnitski and T. Kalamees (2015). Field Survey of Overheating Problems in Estonian Apartment Buildings, Architectural Science Research, vol. 58, no.1. pp.

NABERS (2012) 'National Australian Built Environment Rating System', http://www.nabers.com.au/

NASA (2012) Design Process For Complex Electronics.

http://www.hq.nasa.gov/office/codeq/software/ComplexElectronics/ce_design.htm

Ní Riain C., Fisher J., MacKenzie F., Littler J. (2000) BRE's Environmental Building: Energy Performance in Use CIBSE/ASHRAE Conference "20 20 Vision" in Dublin, September 2000

Passive House Institute (PHI) (2012) http://www.passiv.de/en/index.html

PROBE 14 (1998) 'Elizabeth Fry Building' BSJ April 1998, http://www.uea.ac.uk/estates/environmentalpolicy/Probe+report

Pyzdek T. (2003). Quality Engineering Handbook, 2nd Edition, ISBN 0824746147

RAE (2010) ‘Engineering a Low Carbon Future’ ISBN: 1-903496-51-9 
RIBA (2012) BIM Overlay to the Outline Plan of Work. http://www.ribabookshops.com/planof-work/

RIBA (2011) Green Overlay to the RIBA Outline Plan of Work. RIBA Publishing, 15 Bonhill Street, London. ISBN 9781859464410

Tovey K. and Turner C. (2006) Carbon reduction strategies at University of East Anglia, U', Proceedings of the Institution of Civil Engineers, Municipal Engineer 159, December 2006 Issue ME4 Pages 193-201.

Tuohy P.G (2008) Air-conditioning: The impact of UK regulations, the risks of un-necessary air-conditioning and a capability index for non-air conditioned naturally ventilated buildings. Cumberland Lodge, Windsor, UK, 27-29 July 2008. London: Network for Comfort and Energy Use in Buildings, http://nceub.org.uk.

Tuohy P.G and Murphy G (2015) Closing the Gap in Building Performance: Learning from other BIM benchmark Industries. Architectural Science Review, vol 58, no. 1, pp.

Tuohy, P.G. (2009) Regulations and robust low-carbon buildings. Building Research and Information, Special Issue: Cooling in a Low-Carbon World, 37, (4), 433-445, Taylor \& Francis, 1 July 2009. ISSN: 0961-3218.

Tuohy, Paul Gerard (2009a) 'Simulation and BIM in building design, commissioning and operation: a comparison with the microelectronics industry'. In: Building Simulation 2009, 11th International Building Performance Simulation Association Conference, 2009-07-27 2009-07-30, Glasgow, UK.

Tuohy, Paul Gerard, Murphy, Gavin Bruce, Deveci, Gokay (2012) Lessons from Post Occupancy Evaluation and Monitoring of the 1st Certified Passive House in Scotland. Passivhus Norden Conference, 2012-10-21 - 2012-10-23, Trondheim.

Tuohy P G (2013) Strategies for low carbon buildings: Assessment of design options and translation of design intent into performance in practice. PhD Thesis, University of Strathclyde, 2013. https://pure.strath.ac.uk

Turner C and Frankel M (2008) Energy Performance of LEED $®$ for New Construction Buildings. USGBC 2008. http://newbuildings.org/energy-performance-leed-new-constructionbuildings.

USGBC (2012) LEED. http://www.usgbc.org/DisplayPage.aspx?CategoryID=19

Usable Buildings Trust (UBT) (2012) http://www.usablebuildings.co.uk/

Voss K, Herkel S, Pfafferott J, Lohnert G, Wagner A, (2007), Energy efficient office buildings with passive cooling - Results and experiences from a research and demonstration programme. Solar Energy 81 (2007) 424-434.

Way, M. and Bordass, B., 2005. Making feedback and post-occupancy evaluation routine 2: Soft Landings: involving design and building teams in improving performance, Building Research \& Information 33(4), 353-360. 
Zero carbon Hub (2013) Mechanical Ventilation with Heat Recovery in New Homes.

http://www.zerocarbonhub.org/sites/default/files/resources/reports/Mechanical_Ventilation_w ith_Heat_Recovery_in_New_Homes_Final\%20Report.pdf 